\title{
Plântulas e sementes de macrófitas aquáticas de lagoas do Pantanal Sul-Mato-Grossense
}

\author{
Gabriel Tirintan de Lima', Gisele Catian², Gabriel Pesqueira da Luz', \\ Vinícius Manvailer Gonçalves² \& Edna Scremin-Dias²
}

\author{
'Universidade Federal de Mato Grosso do Sul, Instituto de Biociências, Campo Grande, MS, Brazil. \\ gabrieltirintan@gmail.com, gabriel.pesqueira12@gmail.com \\ 2Universidade Federal de Mato Grosso do Sul, Programa de Pós-Graduação Biologia Vegetal, Campo Grande, MS, Brazil. \\ gcatian@gmail.com, v.manvailer@gmail.com, ednascremindias@gmail.com
}

Recebido em 29.II.2016

Aceito em 14.VI.2018

DOI 10.21826/2446-8231201873201

RESUMO - Plântulas e diásporos são de extrema importância na recolonização de ambientes, contribuindo para a estabilização de áreas inundadas. Inexistem dados sistematizados sobre sementes, diásporos e plântulas de espécies de macrófitas que habitam áreas sazonalmente inundáveis do Pantanal. Objetivou-se desenvolver um guia com descrições morfológicas de plântulas, diásporos e sementes, assim como da estratégia de propagação vegetativa de macrófitas, inéditas para algumas espécies. Coletaram-se plântulas, diásporos e sementes em lagoas da subregião do Abobral/Pantanal. Pranchas contendo 24 espécies (14 famílias) foram elaboradas incluindo dados morfológicos e taxonômicos. As famílias e espécies descritas foram: Alismataceae (3 spp.), Araceae (1), Polygonaceae (3), Pontederiaceae (3), Cyperaceae (1), Lentibulariaceae (2), Nymphaeaceae (3), Onagraceae (2), Cabombaceae (1), Cannaceae (1), Hydrocharitaceae (1), Marantaceae (1), Plantaginaceae (1) e Rubiaceae (1), contemplando todas as formas de vida. Algumas espécies apresentam propagação vegetativa (estolão, fragmentação, rizomas e brotação), outras apresentaram somente frutos.

Palavras-chave: atlas, bancos de sementes, diásporo, guia

\begin{abstract}
Seedlings and seeds of aquatic macrophytes from ponds of the Pantanal of Mato Grosso do Sul. Seeds and seedlings are important for re-colonization and stabilize flooded areas. Currently, no systematized data is available for seedlings, seeds, and other diaspores of aquatic macrophyte species from seasonally flooded areas of the Pantanal. We developed a guide describing the morphology and the propagation strategies of diaspores and seedlings, some of which are described for the first time. Plants, seedlings and seeds were collected in ponds from the Pantanal subregion called Abobral. Plates include morphological and taxonomic data of 24 species, distributed in 14 families: Alismataceae (3 spp.), Araceae (1), Polygonaceae (3), Pontederiaceae (3), Cyperaceae (1), Lentibulariaceae (2), Nymphaeaceae (3), Onagraceae (2), Cabombaceae (1), Cannaceae (1), Hydrocharitaceae (1), Marantaceae (1), Plantaginaceae (1) and Rubiaceae (1). This sampling contemplates all life forms of macrophytes. While some species presented mainly vegetative propagation, such as stolon, fragmentation and sprouting, others also developed fruits.
\end{abstract}

Keywords: atlas, diaspore, seed bank, guide

\section{INTRODUÇÃO}

A recolonização da vegetação em um ambiente sujeito a perturbação ocorre principalmente por meio do banco de sementes no solo, o qual apresenta papel fundamental no equilíbrio dinâmico de uma área (Schmitz 1992). A germinação das sementes e a emergência de plântulas de espécies de macrófitas aquáticas são importantes mecanismos para a sobrevivência destas, permitindo a manutenção e regeneração das comunidades em ambientes hidrologicamente dinâmicos como o Pantanal.

As plântulas emergentes do banco reduzem a erosão e a perda de nutrientes após distúrbios, contribuindo para a estabilização de áreas perturbadas (Uhl et al. 1988), a exemplo do que ocorre no Pantanal após a cheia. Esta recolonização é observada em lagoas ou campos alagáveis $\mathrm{e}$, nos momentos da enchente e da vazante, as sementes germinam e as plântulas se desenvolvem a partir do banco existente, firmando a sua importância para a colonização e biodiversidade do Pantanal. Muitas plântulas de macrófitas aquáticas são morfologicamente indistinguíveis, compondo uma nova comunidade de organismos na lâmina d'água. Neste aspecto, trabalhos que envolvam a avaliação da dinâmica sazonal de ambientes alagáveis necessitam se embasar em dados morfológicos de sementes e plântulas, visto a necessidade de identificação destas estruturas.

Ambientes como o Pantanal estão sendo crescentemente perturbados, com vastas áreas de forrageiras introduzidas, em substituição às pastagens nativas; pelo desmatamento de caapões para a expansão da criação de gado; e pela construção de hidroelétricas nas cabeceiras, alterando o fluxo natural de inundação. O entendimento dos processos de regeneração natural e da dinâmica de comunidades vegetacionais é de extrema importância para o sucesso 
do seu manejo (Baker 1989, Daniel \& Jankauskis 1989). Neste contexto, é inevitável que os bancos de sementes e plântulas constituam a base da resiliência na restauração da vegetação.

A importância das sementes como estruturadoras e restauradoras de comunidades ainda não é bem documentada nas planícies de inundação, bem como há relativamente pouco conhecimento sobre a diversidade de estruturas morfológicas e dos tipos de diásporos dispersos pela água das espécies de plantas. Neste aspecto, guias e ou/ atlas de identificação têm importância fundamental para pesquisas de diferentes áreas da ciência, pois permite a efetiva identificação dos diásporos, plântulas e propágulos de espécies de macrófitas aquáticas, fornecendo a base para testes de hipóteses sobre as interações entre banco de sementes e plântulas no Pantanal.

A fim de proporcionar a base do conhecimento para o estudo e identificação de sementes em lagoas do Pantanal e a distinção de plântulas de macrófitas ocorrentes no local, elaborou-se este guia de identificação, que inclui dados morfológicos e taxonômicos com descrições e imagens de plântulas, sementes e diásporos, e quando possível, indicando também a estratégia de propagação vegetativa de espécies de plantas aquáticas ou palustres. Os tratamentos genéricos incluem descrições de espécies com caracteres gerais descrevendo o hábito, a plântula e o diásporo.

\section{MATERIAL E MÉTODOS}

O Pantanal apresenta uma área de aproximadamente $140.000 \mathrm{Km}^{2}$, sendo mais da metade coberta por água na época da cheia (Radam-Brasil 1982) e ocupa 38,21\% da bacia do Alto Paraguai (Silva \& Abdon 1998). Suas paisagens encontram-se diferenciadas pela intensidade $\mathrm{e}$ regularidade do pulso de inundação (Junk et al. 1989, Pozer \& Nogueira 2004), o qual é considerado um fenômeno ecológico importante na região e que ocorre sazonalmente com ciclos de secas e cheias, através do extravasamento da água no leito dos rios para a planície, atuando diretamente na biota existente (Junk et al. 1989, Junk \& Silva 1995).

Vários tratados internacionais estabeleceram a necessidade de inventários e medidas para a proteção deste ecossistema (Darwall et al. 2008, SCBD 2010). Em 1993, o Brasil assinou a Convenção de Ramsar, que pressupõe uma política nacional para a gestão inteligente e proteção das áreas úmidas e sua biodiversidade. Considerado como a maior planície alagada contínua do mundo, o Pantanal consiste em um mosaico de lagoas, brejos permanentes e sazonais, e vasta extensão de campos que são periodicamente alagáveis (Guarim et al. 2000).

O clima da região é tropical subúmido - Aw (Koeppen 1948), com invernos secos e verões chuvosos, e a precipitação média anual oscila entre 1.000 e $1.200 \mathrm{~mm}$, concentrando-se entre novembro e abril (Soriano et al.
2001). Os ecossistemas contribuintes para a biota do Pantanal possuem elementos florísticos dos Cerrados e Cerradões (em áreas sem alagamento periódico), campos inundáveis e ambientes aquáticos (como lagoas de água doce ou salobra, rios, vazantes, corixos), cujos solos são altamente arenosos (Abdon et al. 1998).

As sementes, diásporos e plântulas foram coletadas em lagoas localizadas na subregião do Abobral, município de Corumbá, Mato Grosso do Sul (19 $23^{\circ} 57,87^{\prime}$ 'S; $57^{\circ} 02^{\prime} 18,69^{\prime}$ 'O; $90 \mathrm{~m}$ de altitude). As plântulas foram coletadas manualmente sob a lâmina d'água, durante o alagamento, dentro de e/ou no solo umedecido destas durante a vazante. As sementes foram oriundas do projeto de doutorado da coautora Gisele Catian, a qual coletou o solo em 20 lagoas (oito amostras por lagoa) e triando-as para identificação (Bonis et al. 1995) para identificação. Fotos das sementes foram tiradas em estereomicroscópio com câmera acoplada. Plantas adultas, plântulas, propágulos, infrutescências e frutos foram fotografados em campo e no laboratório.

Para a identificação das sementes foram utilizados frutos das espécies in loco, assim como para as plântulas. A classificação taxonômica das ordens e famílias seguiu o sistema APG IV - Angiosperm Phylogeny Group (2016) e a nomenclatura científica das espécies botânicas foi verificada pela base de dados da Lista de Espécies da Flora do Brasil (Flora do Brasil 2014, acessado em 10/10/2014). Para a identificação das plantas utilizou-se Pott \& Pott (2000) e para as formas biológicas Irgang \& Gastal Jr. (1996) e Tur (1972).

\section{RESULTADOS E DISCUSSÃO}

São apresentadas 24 espécies, compondo 14 famílias botânicas: Alismataceae (3 espécies), Araceae (1), Polygonaceae (3), Pontederiaceae (3), Cyperaceae (1), Lentibulariaceae (2), Nymphaeaceae (3), Onagraceae (2), Cabombaceae (1), Cannaceae (1), Hydrocharitaceae (1), Marantaceae (1), Plantaginaceae (1) e Rubiaceae (1). Algumas espécies apresentaram-se no campo com estratégias de propagação vegetativa, enquanto outras apresentaram frutos desenvolvidos, documentados nas figuras 1 a 12.

\section{Pistia stratiotes L.}

(Figs. 1A-D)

Erva aquática flutuante livre anual ou perene (Cook 1990), propagação por estolão (Pott \& Pott 2000) (Fig. 1A). Pertence à família Araceae, ordem Alismatales (APG IV 2016).

Plântula: semelhante à planta madura, em tamanho menor, muitas vezes ligada por estolão com a planta mãe; folhas sésseis ovaladas com tricomas, sem disposição em 

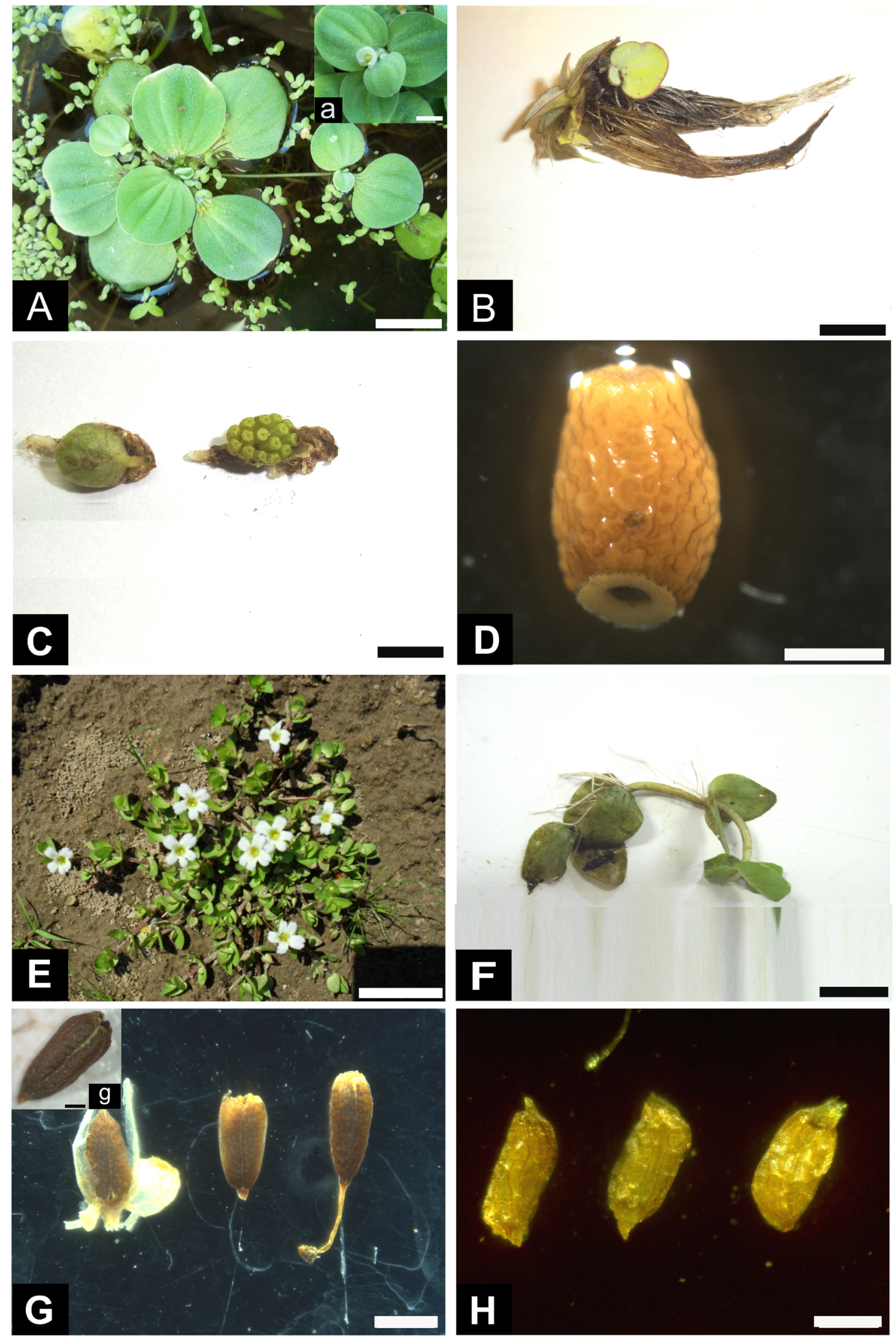

Figs. 1A-H. A-D. Pistia stratiotes. A. planta com estolão ligado à plântula, a. flor; B. plântula; C. diásporo; D. semente. E-H. Bacopa australis. E. planta; F. plântula; G. sementes dentro do diásporo, g. diásporo; H. semente. Barras: Figs. A, a, B, C, E, F = $1 \mathrm{~cm} ; \mathbf{F i g} . \mathbf{D}=1 \mathrm{~mm}$; Figs. G, g $=2 \mathrm{~mm}$; Fig. $\mathbf{H}=200 \mu \mathrm{m}$. 
roseta, coloração verde um tom mais claro que a plantamãe (Fig. 1B).

Diásporo: fruto cápsula ovóide (Fig. 1C) marrom quando maduro, submersa na água; sementes em formato de "barril", redondas achatadas nas pontas, quando maduras são beges a alaranjadas e com rugosidades no tegumento (Fig. 1D), após destacadas do fruto boiam na água, assemelhando-se a rolhas.

\section{Bacopa australis V.C. Souza}

(Figs. 1E-H)

Erva aquática perene emergente na seca e submersa na cheia (Pott \& Pott 2000) (Fig. 1E). Pertence à família Plantaginaceae, ordem Lamiales (APG IV 2016).

Plântula: semelhante à planta madura, menor tamanho, caule cilíndrico, folhas opostas orbiculares a suborbiculares, pouco fragmentada, de coloração verde quando no seco, e avermelhado na água, podendo ser confundida com Diodia kuntzei K. Schum. quando na água, porém as folhas são ovais (Fig. 1F).

Diásporo: cápsula ovóide não carnosa (Fig. 1G), marrom quando madura (Fig. 1g); semente fusiforme, estriada, rugosa, amarela, tegumento reticulado (Fig. 1H).

\section{Cabomba furcata Schult. \& Schult. f.}

(Figs. 2A-D)

Erva aquática perene submersa fixa (Pivari 2009) (Fig. 2A), pode propagar-se através de fragmentos do caule (Pott $\&$ Pott 2000). Pertence à família Cabombaceae, ordem Nymphaeales (APG IV 2016).

Plântula: semelhante à planta madura, menor tamanho; folhas submersas com três folhas por verticilo, caule delicado e quebradiço, não apresenta folhas flutuantes sagitadas utilizadas para suportar as flores fora da água. Muitas vezes ocorre fragmentação do caule e os fragmentos se comportam como propágulos, que são soltos na água e levados pela correnteza, desenvolvendo raízes e se fixando no solo (Fig. 2B).

Diásporo: fruto carpídio (Lima et al. 2012), protegido por perianto, pericarpo coriáceo amarelado (Lima et al. 2014) (Fig. 2C); semente orbicular (Lima et al. 2014) castanho escuro, operculada, disco epígino, mais ou menos achatado e cilíndrico; tegumento apresenta tricomas membranosos (Fig. 2D).

Diodia kuntzei K. Schum.

(Figs. 2E-H)

Erva anfíbia perene, submersa na cheia (Fig. 2E), propagam-se através de mudas obtidas por divisão do caule, que enraíza nos nós, e estolão (Pott \& Pott 2000). Pertence à família Rubiaceae, ordem Gentianales (APG IV 2016).
Plântula: semelhante à planta madura, com tamanho menor, caule tetrágono e glabro, folhas sésseis oblongas com tricomas axilares (Fig. 2F); pode apresentar coloração avermelhada; é confundida com Rotala ramosior (L.) Koehne, mas é distinguida pela falta de marcas no verticilo foliar, presente no caule a partir da segunda folha.

Diásporo: fruto cápsula, liso, glabro, elipsóide (Bacigalupo \& Cabral 1999) (Fig. 2G) que se separa longitudinalmente em dois com uma semente por mericarpo; semente única de contorno subelíptico, superfície reticulada com uma saliência longitudinal mediana, coloração marrom a preto (Fig. 2H).

\section{Polygonum ferrugineum Wedd}

(Figs. 3A-D)

Erva aquática emergente, às vezes flutuante ou anfíbia perene (Fig. 3A), propaga-se por mudas ou por pedaços da base do caule, que enraízam nos nós (Pott \& Pott 2000). Pertence à família Polygonaceae, ordem Caryophyllales (APG IV 2016).

Plântula: semelhante à planta madura, em menor tamanho, caule cilíndrico, folhas alternas lanceoladas, sendo totalmente esbranquiçadas e pilosas (Fig. 3B).

Diásporo: fruto lenticular (Melo 1996) em núcula (Fig. 3C); semente subarredondada marrom lisa e brilhante, com duas faces iguais em largura, com ápice pontiagudo, e resquício de estigma (Fig. 3D). Distingue-se dos diásporos de outras espécies de Polygonum, por apresentar-se dorsoventralmente mais achatado.

\section{Polygonum hispidum Kunth}

$$
\text { (Figs. 3E-H) }
$$

Erva aquática emergente (Fig. 3E), propaga-se por pedaços de caule, enraizando nos nós (Pott \& Pott 2000). Pertence à família Polygonaceae, ordem Caryophyllales (APG IV 2016).

Plântula: apresenta-se igual à planta madura, porém em menor tamanho, folha pegajosa oval-lanceolada com ócrea similar à adulta, com pilosidade na folha e no caule (Fig. 3F).

Diásporo: fruto lenticular (Melo 1996) em núcula, de pericarpo fino, envolvida pelo cálice acrescente (Fig. 3G); semente ovalada-côncava, marrom-escura ou pretas lisas lustrosas, sem indumento no endocarpo e com estilete central remanescente e ápice acuminado, mais arredondada do que a $P$. ferrugineum (Fig. $3 \mathrm{H}$ ).

\section{Polygonum punctatum Elliott}

(Figs. 4A-D)

Erva perene emergente ou anfíbia (Fig. 4A), propaga-se por pedaços da base do caule que enraízam nos nós (Pott 

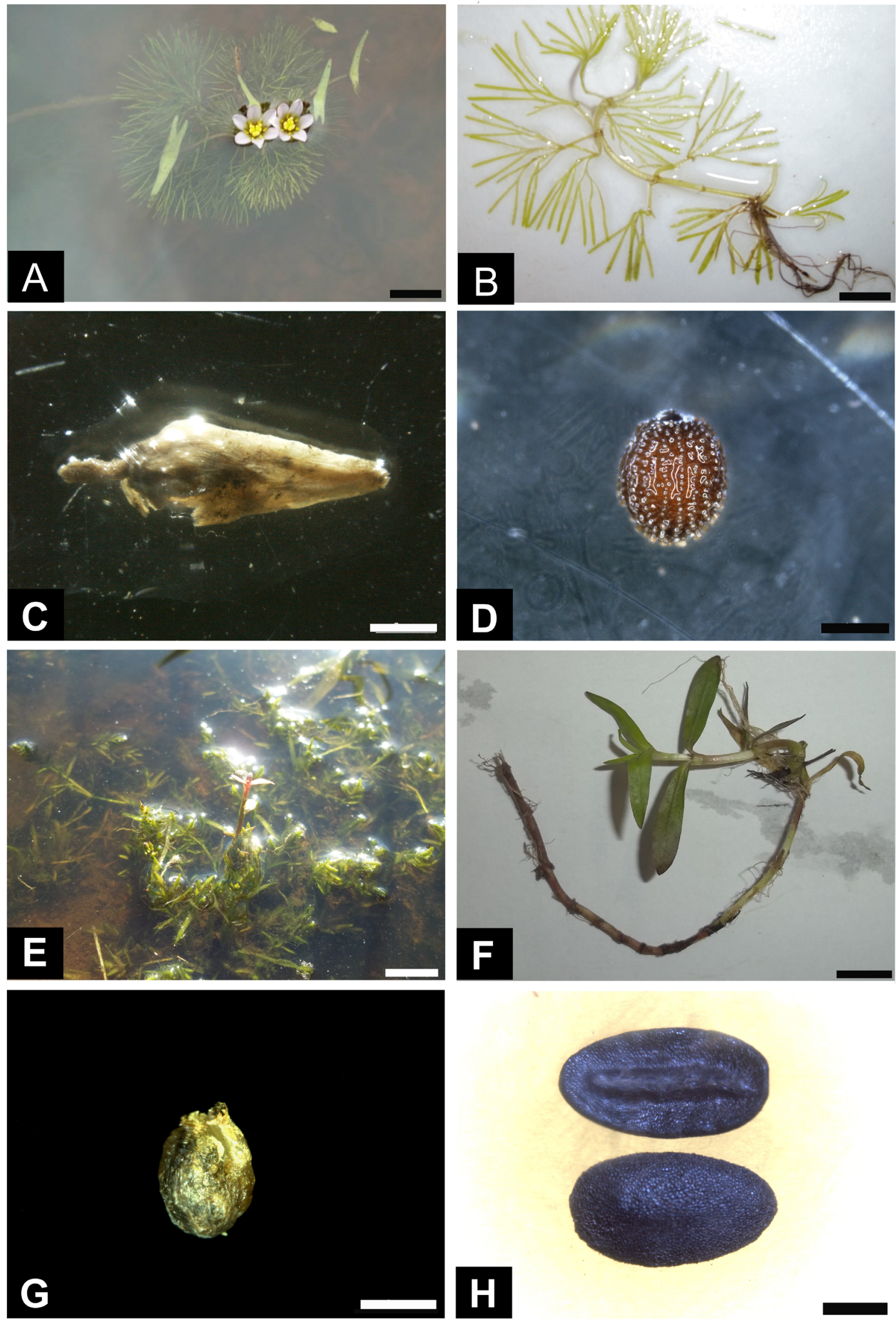

Figs. 2A-H. A-D. Cabomba furcata. A. planta com folhas submersas e flutuantes sagitadas; B. plântula; C. diásporo; D. semente. E-H. Diodia kuntzei. E. planta; F. plântula; G. diásporo; H. semente. Barras: Figs. A, B, E, F =1 cm; Fig. C= 2 mm; Figs. D, G, H=1 mm. 

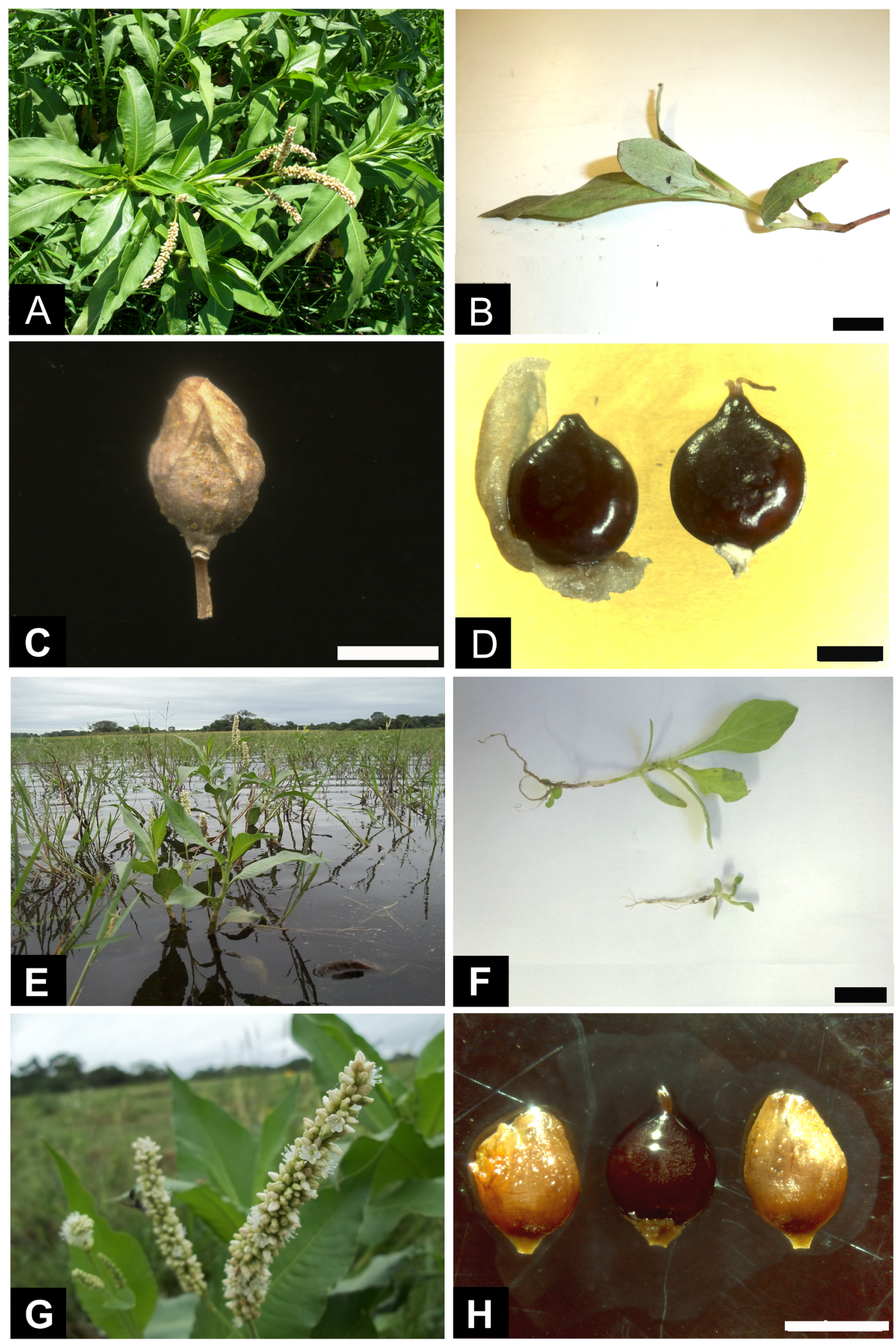

Figs. 3A-H. A-D. Polygonum ferrugineum. A. planta; B. plântula; C. diásporo; D. semente. E-H. Polygonum hispidum. E. Planta; F. plântula; G. inflorescência; H. semente. Barras: Figs. B, F =1 cm; Figs. C, H=2 mm; Fig. $\mathbf{D}=1 \mathrm{~mm}$. 

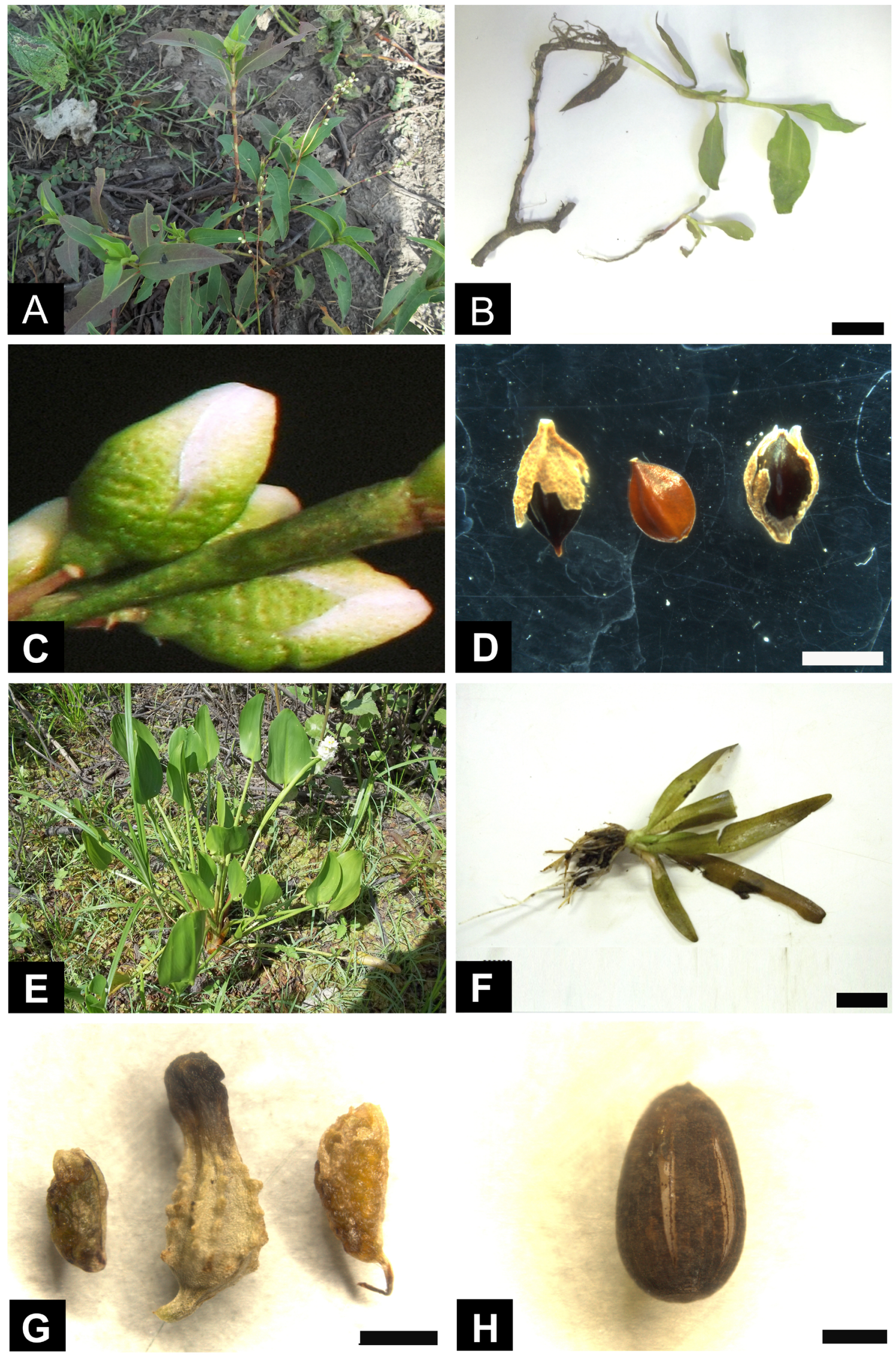

Figs. 4A-H. A-D. Polygonum punctatum. A. planta; B. plântula; C. botão floral com pontuações; D. semente. E-H. Pontederia parviflora. E. planta; F. plântula; G. diásporo; H. semente. Barras: Figs. B, F =1 cm; Figs. D, G. $=2 \mathrm{~mm}$; Fig. H $=1 \mathrm{~mm}$. 
\& Pott 2000). Pertence à família Polygonaceae, ordem Caryophyllales (APG IV 2016).

Plântula: apresenta-se igual à planta madura, caule ereto avermelhado, folha lanceolada, porém sem as glândulas no limbo e de cor avermelhada (Fig. 4B).

Diásporo: fruto lenticular trígono (Melo 1996) em núcula, com perigônio pontuado por glândulas (Fig. 4C); semente com três faces iguais em largura, com ápice pontiagudo, envolvida pelo cálice acrescente, perianto frutífero punctato-glanduloso (Melo 1996); formato arredondada a ovada, marrom-escura ou pretas lustrosas, sem indumento no endocarpo e com estilete central remanescente (Fig. 4D), menor que as sementes de P. ferrugineum e P. hispidum.

\section{Pontederia parviflora Alexander}

(Figs. 4E-H)

Erva aquática perene emergente (Fig. 4E), propagase por divisões de touceira (rizomas) (Pott \& Pott 2000). Pertence à família Pontederiaceae, ordem Commelinales (APG IV 2016).

Plântula: apresenta heterofilia, com folhas lineares compridas diferentes das folhas maduras (ovadas-cordadas), finas e membranosas, e folhas lanceoladas em menor tamanho (Fig. 4F). Pode ser confundida com outras espécies de Pontederia e com Hydrocleys nymphoides (Willd.), entretanto estas apresentam pecíolos maiores.

Diásporo: fruto aquênio, achatados dorsiventralmente, superfície costelada (Matias \& Souza 2011), diásporo rugoso e em forma de botão floral (Fig. 4G), submerso na água; semente formato obovóide, preta, lisa, com costelas longitudinais de coloração clara (Fig. 4H).

\section{Eichhornia azurea (Sw.) Kunth}

(Figs. 5A-D)

Erva aquática perene flutuante fixa (Fig. 5A), propagase por brotação de gemas axilares e rizomas (Pott \& Pott 2000). Pertence à família Pontederiaceae, ordem Commelinales (APG IV 2016).

Plântula: folhas lineares espiraladas, submersa na água apresenta crescimento vertical, porém no solo, apresentase com crescimento espiralado típico (Fig. 5B). Quando mais desenvolvida apresenta heterofilia, com folhas finas e compridas na base e folhas obovadas emersas e mais resistentes no ápice da planta (Fig. 5b).

Diásporo: fruto utrículo fusiforme (Nascimento et al. 2013), submerso na água (Fig. 5C); sementes oblongas achatadas lateralmente, apiculadas (Nascimento et al. 2013), com linhas longitudinais uniformemente espaçados em torno desta, semelhantes a costelas, porém menos evidentes do que as encontradas na Eichhornia crassipes; castanho-escuro a preto, com tricomas no endocarpo e superfície com estrias horizontais finas entre os cumes.
Hilo, muitas vezes com funículo; calaza obtusa e muitas vezes de cor mais escura (Fig. 5D).

\section{Eichhornia crassipes (Mart.) Solms \\ (Figs. 5E-H)}

Erva aquática perene flutuante livre (Fig. 5E), propagase por estolões (Pott \& Pott 2000). Pertence à família Pontederiaceae, ordem Commelinales (APG IV 2016).

Plântula: semelhante à planta madura, porém em tamanho diminuto, com folha obovada e brilhante (Fig. 5F), no seco pode apresentar o pecíolo achatado (Fig. 5f), muitas vezes, ligada por estolões à planta mãe (Fig. 5G).

Diásporo: fruto utrículo loculicida (Nascimento et al. 2013), incluso no perianto, submerso na água; semente de formato oblonga, castanho-escuro a preto, com linhas longitudinais uniformemente espaçados em torno desta, semelhantes a costelas (Fig. $5 \mathrm{H}$ ), entretanto mais visíveis do que na $E$. azurea; calaza terminal como uma mancha circular mais escura; menor do que a semente de $E$. azurea com cerca de $1 \mathrm{~mm}$ de diâmetro.

\section{Echinodorus paniculatus Micheli}

(Figs. 6A-D)

Erva aquática perene emergente (Fig. 6A), propagase por estolão (Pott \& Pott 2000) e pseudoviviparidade (Matias 2007), emitindo plântulas nos nós de seus escapos florais. Pertence à família Alismataceae, ordem Alismatales (APG IV 2016).

Plântula: apresenta heterofilia, com folhas lineares finas e com nervuras salientes, e algumas folhas oval-lanceoladas mais desenvolvidas similares às das plantas adultas, porém diminutas, mas com a mesma textura (Fig. 6B).

Diásporo: fruto tipo aquênio obovado (Fig. 6C); semente oblonga, preta, envolta geralmente por um tegumento membranoso, embrião recurvado em forma de $U$ e apresenta tegumento com ornamentação reticulada e tricomas (Fig. 6D).

\section{Helanthium tenellum (Martius) Britton}

(Figs. 6E-H)

Erva aquática anual ou perene anfíbia, submersa na cheia, mas ocorre em solo seco (Fig. 6E), propaga-se através de estolão ou touceiras e rizoma (Pott \& Pott 2000). Pertence à família Alismataceae, ordem Alismatales (APG IV 2016).

Plântula: apresenta folhas lineares e membranosas, podendo ser confundida com Pontederia parviflora Alexander, porém apresenta folhas mais finas, filodiais e não apresenta heterofilia; muitas vezes está unida a outro indivíduo por estolões (Fig. 6F).

Diásporo: fruto aquênio obovado (Fig. 6G); semente auriculiforme, pardo-amarelada, superfície semilisa, 

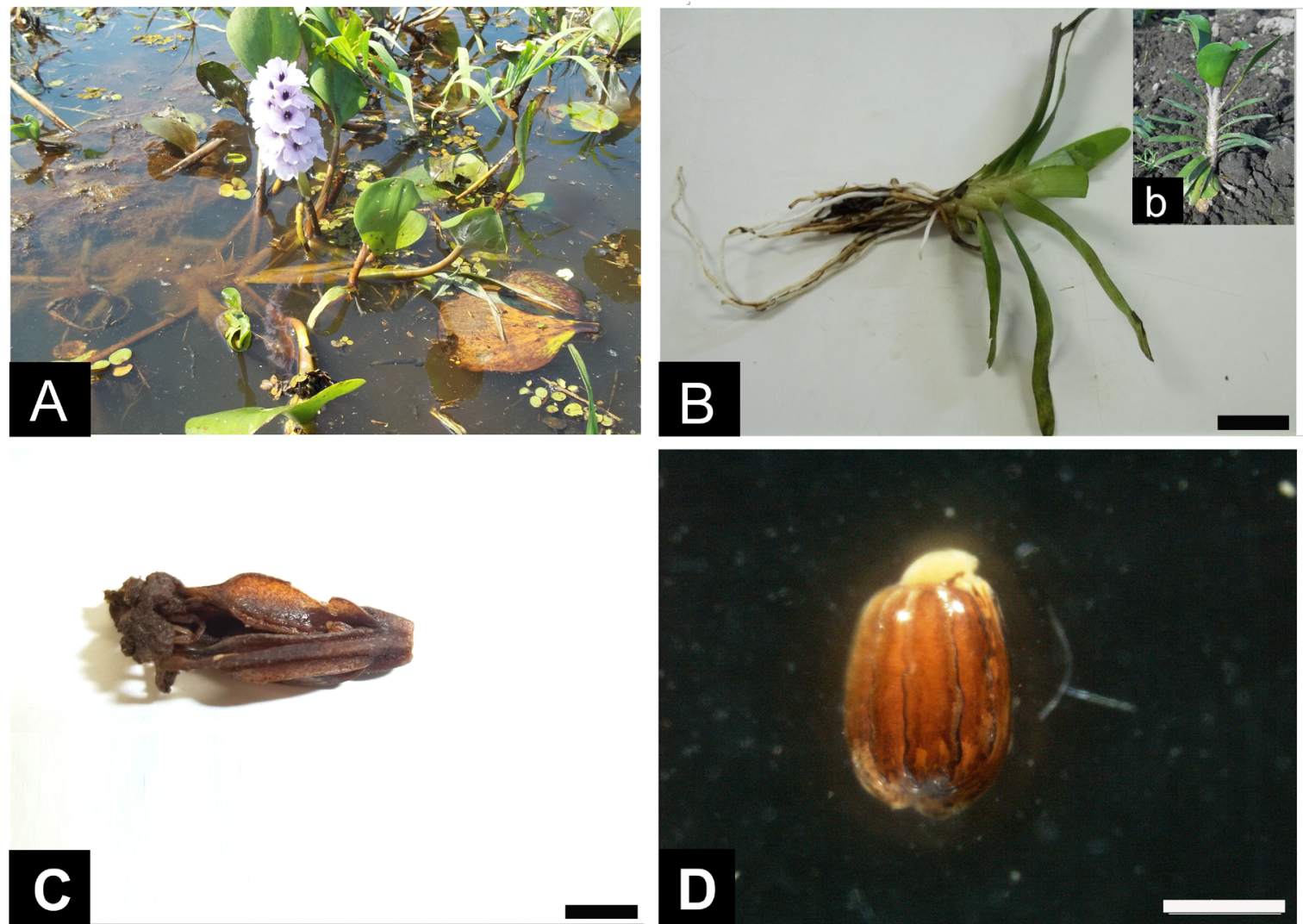

\section{C}
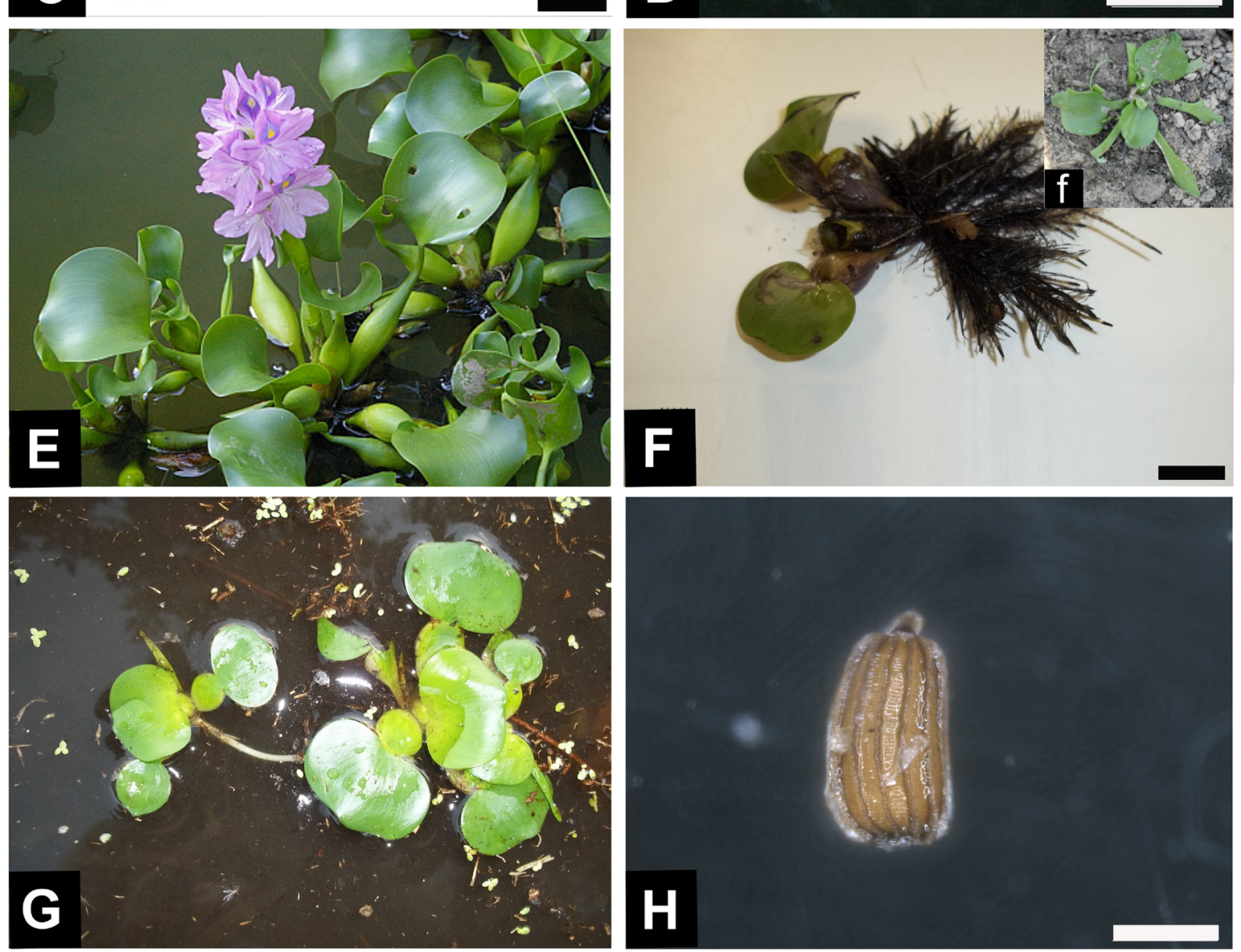

Figs. 5A-H. A-D. Eichhornia azurea. A. Planta; B. plântula, b. plântula com heterofilia; C. detalhe da semente germinando; D. semente. E-H. Eichhornia crassipes. E. Planta; F. plântula, f. plântula com pecíolo achatado; G. detalhe do estolão unindo as plântulas; H. semente. Barras: Figs. B, C, F $=1 \mathrm{~cm} ;$ Fig. $\mathbf{D}=1 \mathrm{~mm}$; Fig. $\mathbf{G}=8 \mathrm{~cm} ; \mathbf{F i g} . \mathbf{H}=500 \mu \mathrm{m}$ 

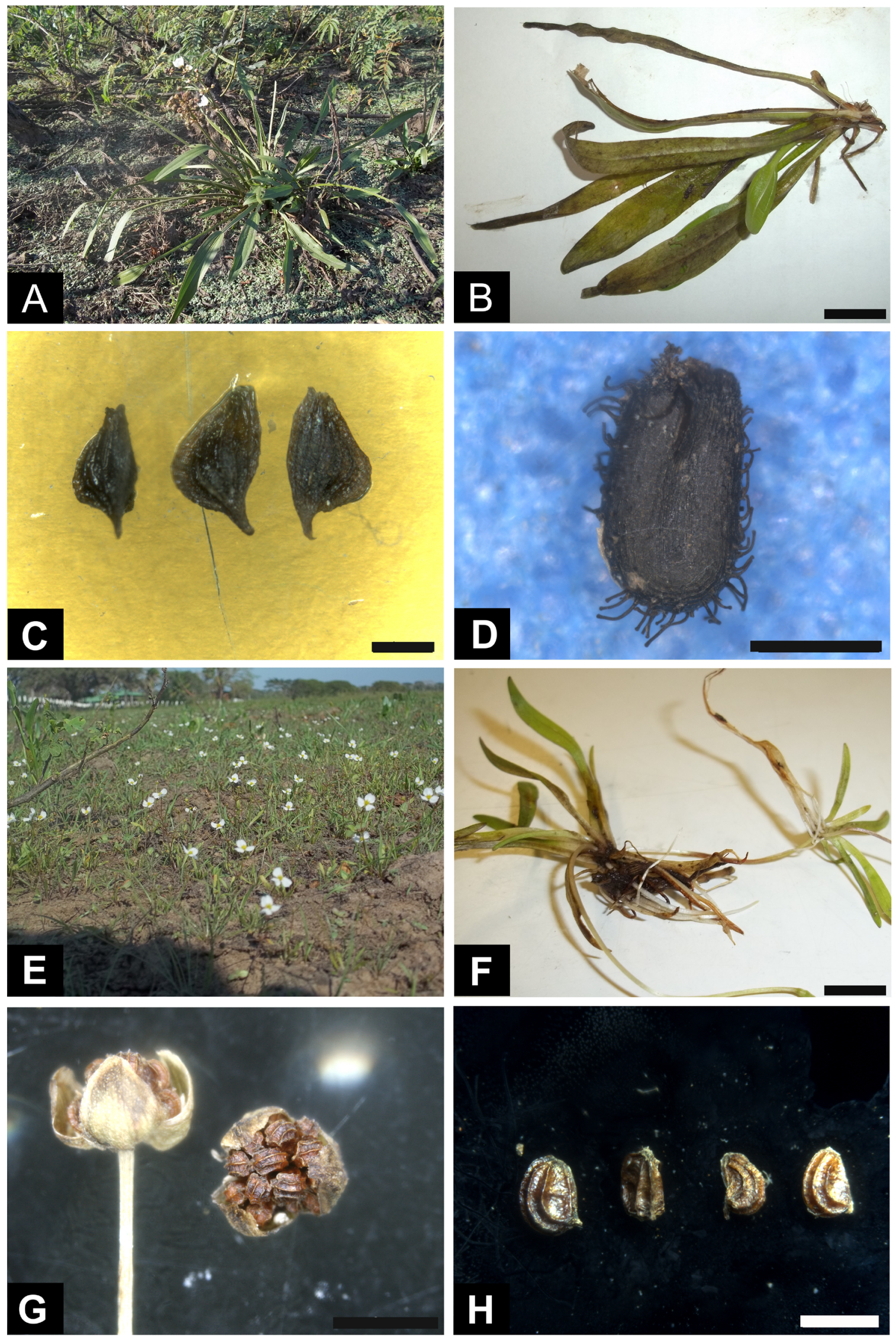

Figs. 6A-H. A-D. Echinodorus paniculatus. A. planta; B. plântula; C. diásporo; D. semente. E-H. Helanthium tenellum. E. planta; F. plântula com detalhe de estolões unindo à planta-mãe; G. diásporo; H. semente. Barras: Figs. B, F =1 cm; Figs. C, H=1 mm; Fig. D = $500 \mu \mathrm{m} ; \mathbf{F i g} . \mathbf{G}=2 \mathrm{~mm}$ 

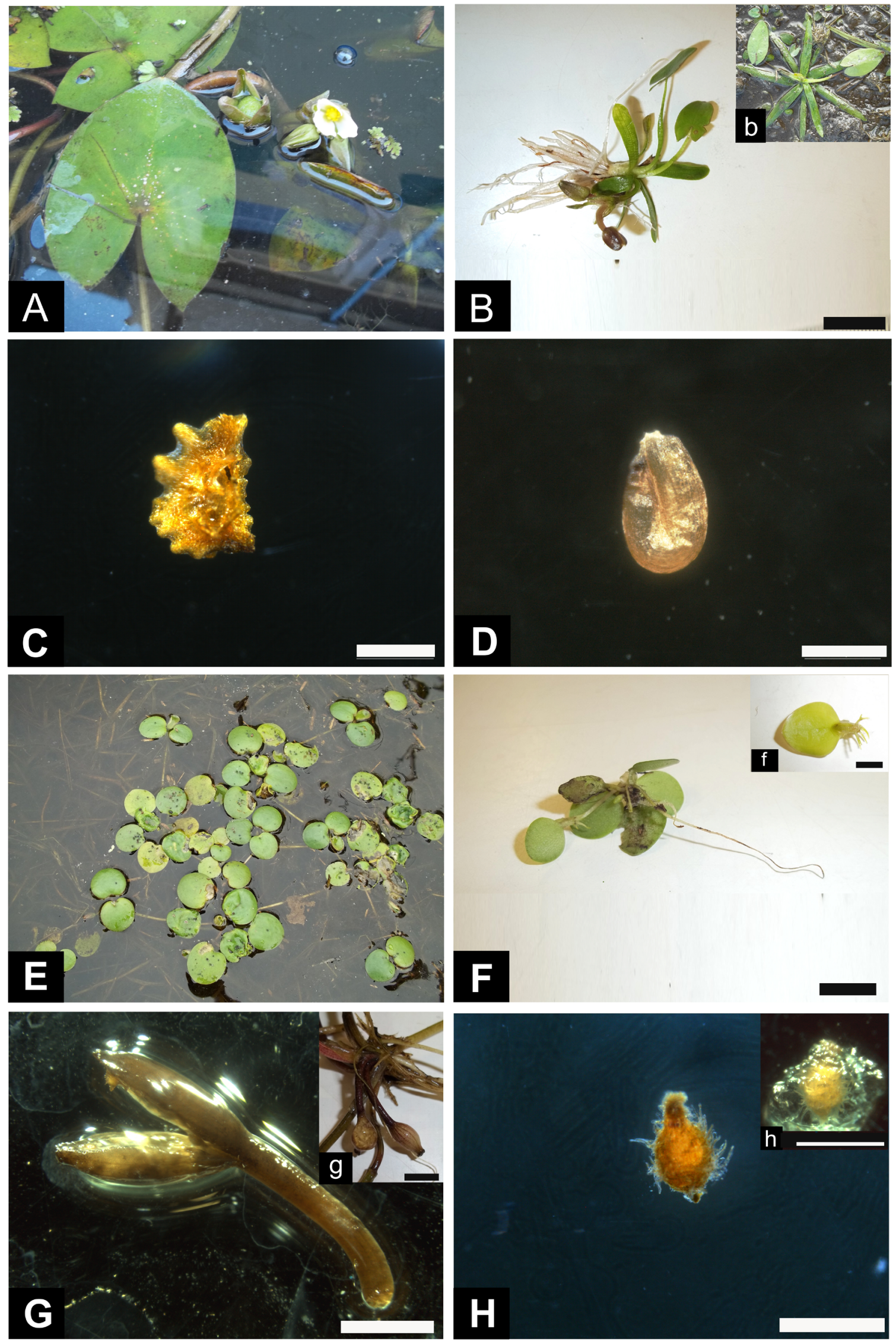

Figs. 7A-H. A-D. Sagittaria guayanensis. A. planta; B, b. plântula; C. diásporo; D. semente. E-H. Limnobium laevigatum. E. planta com estolões unindo vários indivíduos; F, f. plântula; G, g. diásporo; H, h. semente. Barras: Figs. B, F, f=1cm; Figs. C, H=1 mm; Fig. D = $500 \mu \mathrm{m} ;$ Fig. G $=$ $5 \mathrm{~mm}$; Fig. h $=2 \mathrm{~mm}$. 
ornamentação tênue-costelada no tegumento (Matias 2007) (Fig. 6H).

\section{Sagittaria guayanensis Kunth}

(Figs. 7A-D)

Erva aquática flutuante fixa perene (Fig. 7A), propagase por rizoma e tubérculos (Pott \& Pott 2000). Pertence à família Alismataceae, ordem Alismatales (APG IV 2016).

Plântula: semelhante à planta madura, em tamanho menor, apresenta heterofilia, com folhas filiformes e folhas sagitadas menores, mas inicialmente somente filiformes (Figs. 7B e b). Pode apresentar flores, mesmo quando plântula.

Diásporo: fruto aquênio, alado, obovado a orbicular, flutuante na água (Fig. 7C); semente semelhante à de espécies de Echinodorus, com embrião curvo-linear, entretanto marrom-amarelada ou dourada (Fig. 7D).

Limnobium laevigatum (Humb. \& Bonpl. ex Willd.) Heine

(Figs. 7E-H)

Erva aquática perene flutuante livre (Fig. 7E), propagase por fragmentação dos segmentos do estolão (Pott \& Pott 2000). Pertence à família Hydrocharitaceae, ordem Alismatales (APG IV 2016).

Plântula: crescem em rosetas de folhas flutuantes que estão prostradas sobre a superfície da água (Fig. 7F), podendo somente uma folha começar a emitir raízes (Fig. 7f), sem a presença de tecido esponjoso, aerênquima na superfície abaxial da folha.

Diásporo: fruto baga, submerso na água (Figs. 7G e g); semente elipsoidal com um bico curto micropilar no ápice e um funículo persistente na base, a superfície coberta com tricomas plicados (Fig. 7H), envolta por uma substância gelatinosa (Fig. 7h).

\section{Utricularia foliosa L.}

(Figs. 8A-D)

Erva perene submersa livre (Fig. 8A), propaga-se por fragmentos da planta (Pott \& Pott 2000). Pertence à família Lentibulariaceae, ordem Lamiales (APG IV 2016).

Plântula: fragmento dos estolhos do indivíduo adulto que se desenvolve, formando mais folhas e utrículos, assim como o indivíduo maduro não apresenta raiz (Fig. 8B).

Diásporo: frutos bacáceos, redondos e verdes (Fig. 8C), emergente na água; sementes lenticuladas, achatadas, com cicatriz no centro, aladas de coloração amarelada, tecido na margem com padrão reticulado transparente e aspecto esponjoso (Fig. 8D), ficam presas a um tecido globoso dourado (Fig. 8c).

\section{Utricularia gibba L.}

(Figs. 8E-H)

Erva aquática submersa livre anual ou perene (Fig. $8 \mathrm{E})$, propaga-se principalmente através de fragmentação (Pott \& Pott 2000). Pertence à família Lentibulariaceae, ordem Lamiales (APG IV 2016).

Plântula: fragmento bem fino, semelhante ao indivíduo adulto com caule delgado, folhas alternas e filiformes e sem raiz, podendo apresentar turions no ápice como estrutura de propagação vegetativa (Fig. 8F).

Diásporo: frutos bacáceos, arredondado e verde (Fig. 8G) com as sementes soltas no interior (Fig. 8g), diferente da $U$. foliosa, emergente na água; sementes lenticuladas, achatadas, coloração branca, envolta por um tecido reticulado com aspecto esponjoso (Fig. $8 \mathrm{H}$ ).

\section{Ludwigia leptocarpa (Nutt.) H. Hara}

(Figs. 9A-D)

Erva aquática anual ou perene (Kissmann 1997) emergente ou anfíbia (Pott \& Pott 2000) (Figs. 9A e C). Pertence à família Onagraceae, ordem Myrtales (APG IV 2016).

Plântula: apresenta-se com caule ereto, folhas alternas lineares, semelhantes às folhas das plantas adultas, porém sem tricomas, coloração arroxeada (Fig. 9B).

Diásporo: fruto tipo cápsula rompente com 4 a 6 lóculos, com pericarpo fino, membranáceo, que se rompe na maturação, como costelas persistentes da parede do fruto (Barroso et al. 1999) (Fig. 9A); sementes com coloração marrom pálido; apresenta formato elíptico e está inserido no endocarpo modificado em forma de ferradura, esponjoso, facilmente retirado. Assemelha-se a um "grão de milho" (Fig. 9D).

\section{Ludwigia octovalvis (Jacq.) P. H. Raven}

(Figs. 9E-H)

Erva aquática anual ou perene anfíbia (Pott \& Pott 2000) (Fig. 9E). Pertence à família Onagraceae, ordem Myrtales (APG IV 2016).

Plântula: apresenta-se arroxeada com folhas arredondadas, alternas, assemelhadas às folhas das plantas adultas, apenas menores. É comum pigmentação avermelhada no caule (Fig. 9F).

Diásporo: fruto tipo cápsula rompente, com pericarpo fino, membranáceo, que se rompe na maturação, deixando soltas de 8 a 10 porções fibrosas, marrom (Barroso et al. 1999) (Fig. 9G); semente suborbicular, coloração castanha, levemente brilhante e glabra; esféricas com estrias no tegumento, o qual é fino-crustáceo; rafe desenvolvida e oca, podendo destacar-se da semente (Fig. 9H), pode ser confundida com Ludwigia lagunae, entretanto esta apresenta menor tamanho (Fig. 9H semente do meio). 

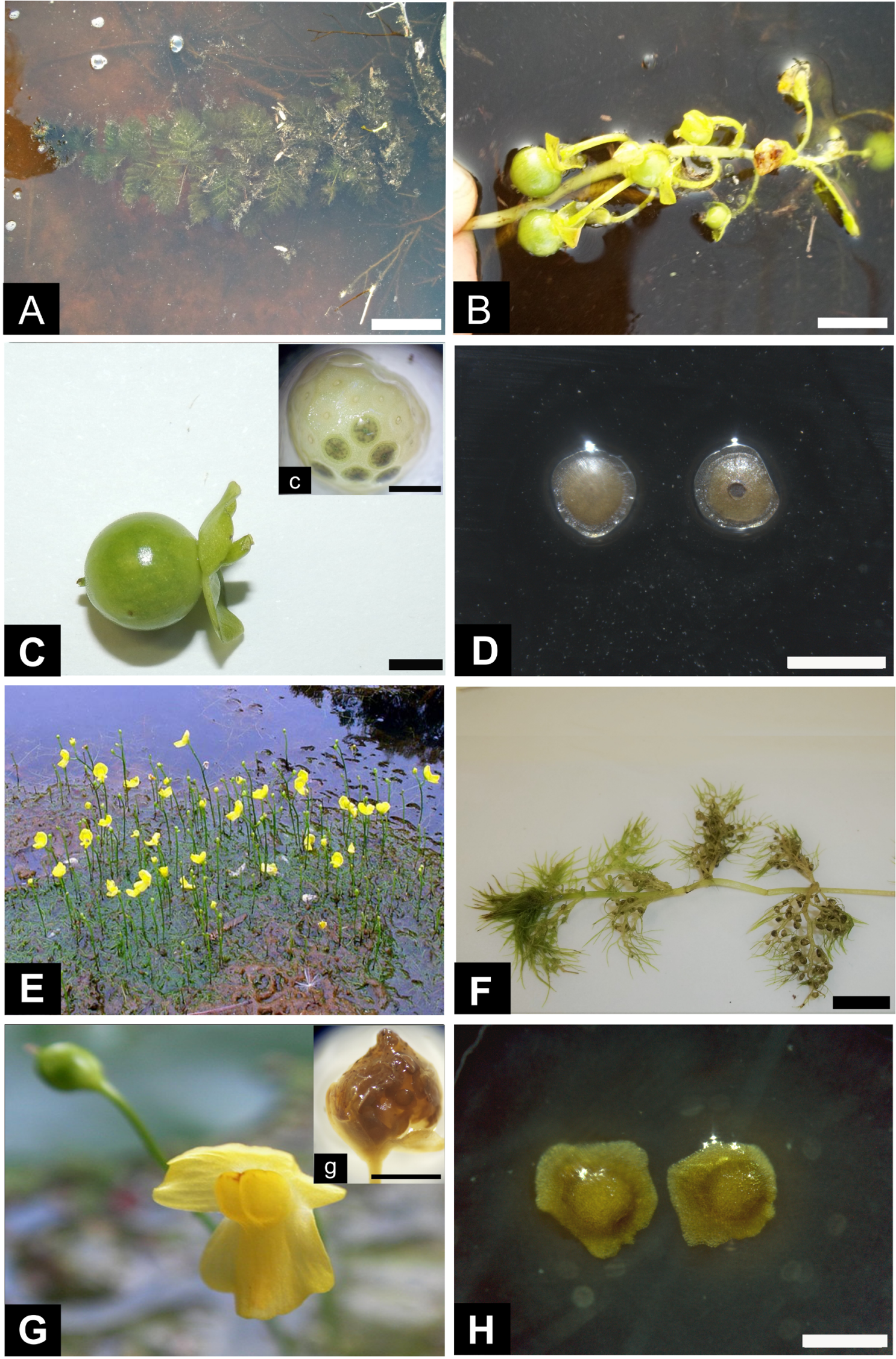

Figs. 8A-H. A-D. Utricularia foliosa. A. planta; B. escapo floral; C, c. diásporo; D. semente. E-H. Utricularia gibba. E. planta; F. plântula com túrion no ápice; G. flor, g. diásporo; H. semente. Barras: Figs. A, B, C, c, F = $1 \mathrm{~cm} ;$ Fig. D = $2 \mathrm{~mm}$; Fig. g = $5 \mathrm{~mm} ; \mathbf{F i g}$. H $=500 \mu \mathrm{m}$. 

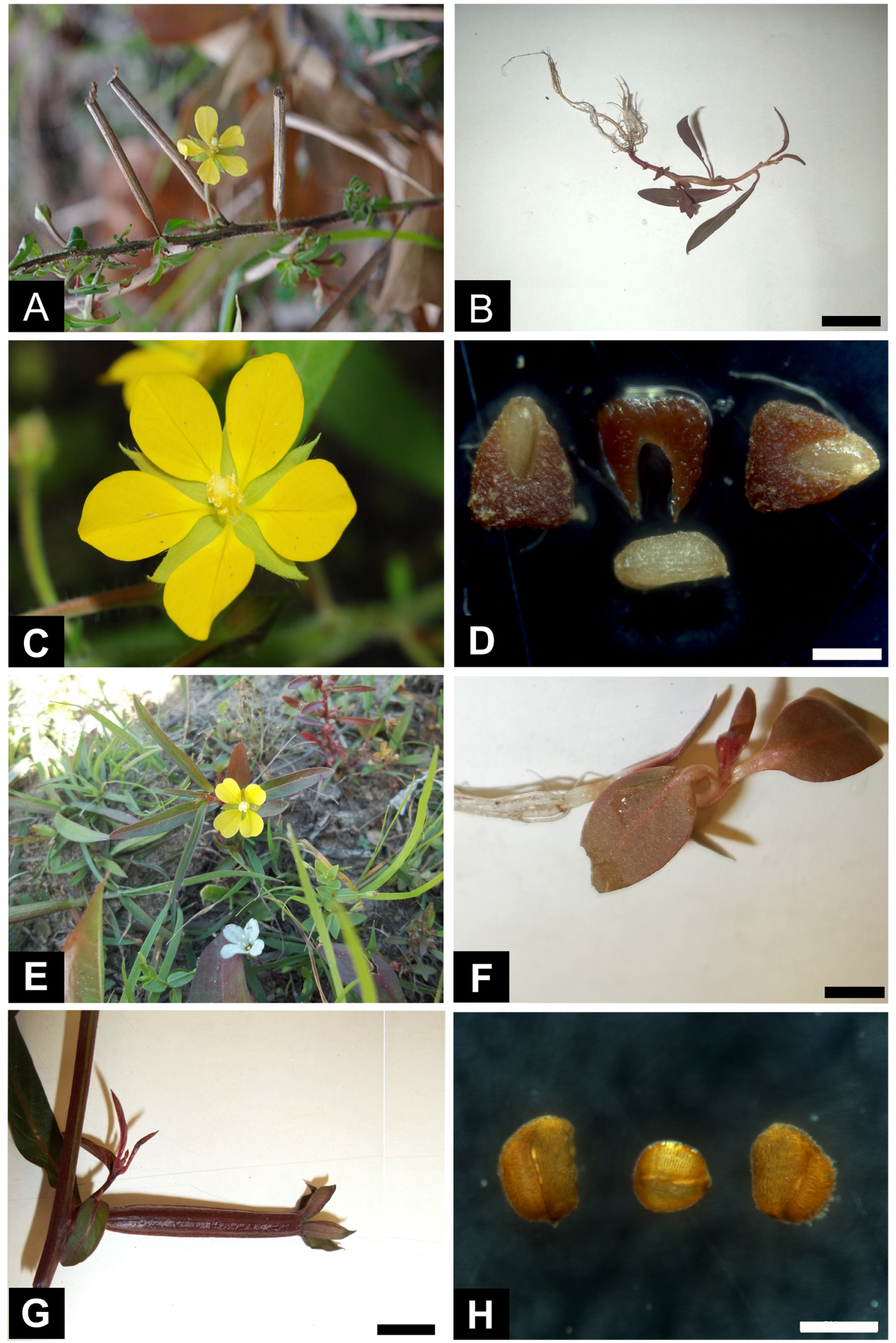

Figs. 9A-H. A-D. Ludwigia leptocarpa. A. planta e diásporo; B. plântula; C. flor; D. semente. E-H. Ludwigia octovalvis. E. planta; F. plântula; G. diásporo; H. semente. Barras: Figs. B, F, $\mathbf{G}=1 \mathrm{~cm}$; Figs. D, $\mathbf{H}=0,5 \mathrm{~mm}$. 

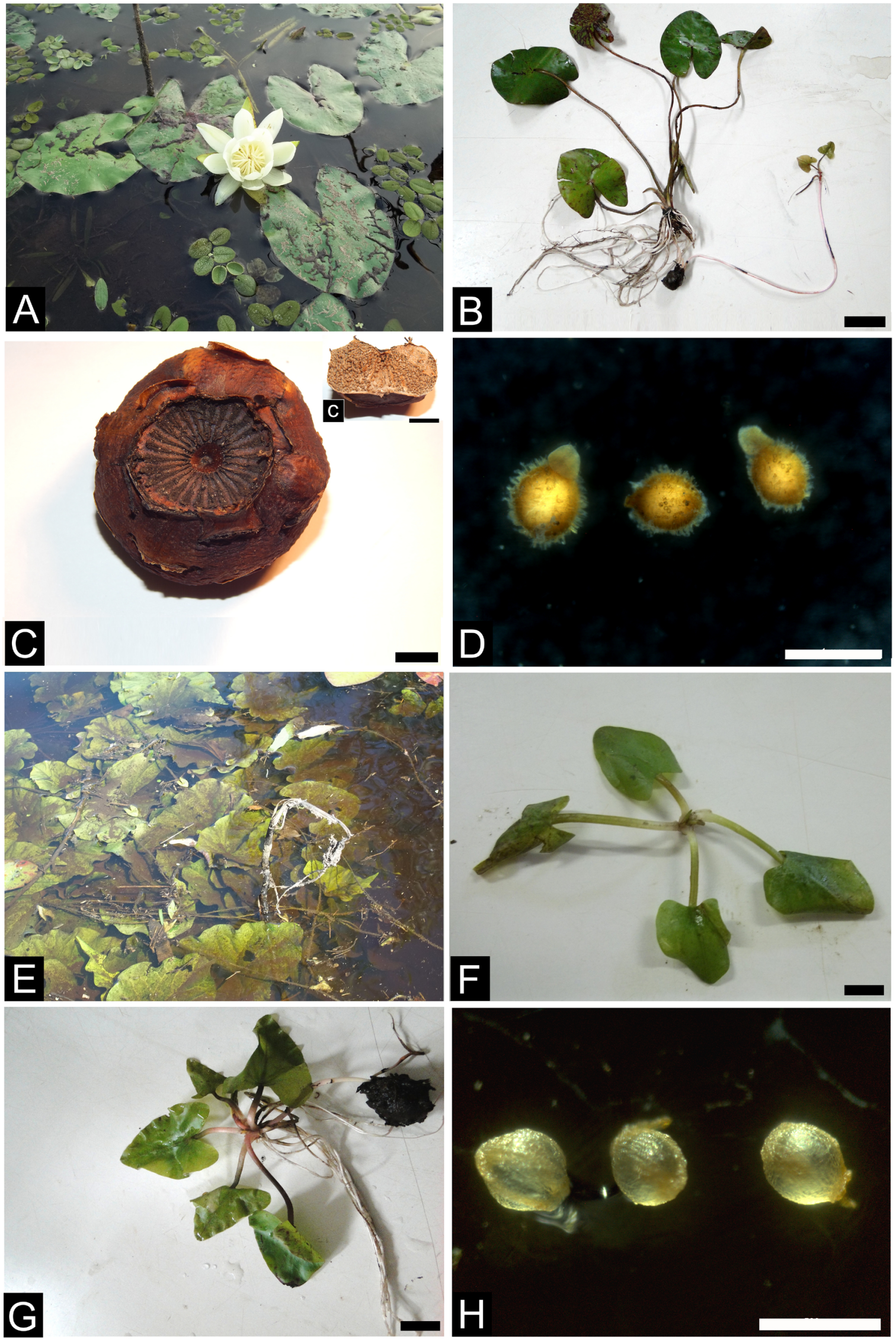

Figs. 10A-H. A-D. Nymphaea amazonum. A. planta; B. plântula com rizoma; C, c. diásporo; D. semente. E-H. Nymphaea oxypetala. E. planta; F. plântula; G. detalhe do rizoma em plântula; H. semente. Barras: Figs. B, C, c, F, G=1 cm; Fig. D =1 mm; Fig. H= $5 \mu \mathrm{m}$. 
Nymphaea amazonum Mart. \& Zucc

(Figs. 10A-D)

Erva aquática perene flutuante fixa (Fig. 10A), propagase por rizoma, brotos e gemas (Pott \& Pott 2000). Pertence à família Nymphaeaceae, ordem Nymphaeales (APG IV 2016).

Plântula: folha mais arredondada, em menor tamanho, esverdeada e membranosa, quando muito pequena, sem o anel de tricomas; fica submersa e, muitas vezes, pode estar fixada a um rizoma (Fig. 10B).

Diásporo: fruto simples bacáceo e plurilocular (Fig. 10C e c), rompe-se irregularmente na maturação (Barroso et al. 1999), submerso na água; semente globosa, provida de opérculo circular e envolvida por arilóide saciforme alvo (Barroso et al. 1999), creme a marrom, com tricomas no tegumento (Fig. 10D).

\section{Nymphaea oxypetala Planch}

(Figs. 10E-H)

Erva aquática perene submersa e flutuante fixa (Fig. $10 \mathrm{E}$ ), propaga-se através de estolão e rizomas (Pott \& Pott 2000). Pertence à família Nymphaeaceae, ordem Nymphaeales (APG IV 2016).

Plântula: diferentemente da planta madura, não apresenta heterofilia, apresenta-se submersa, com folhas sagitadas, sem anel de tricomas nas folhas de qualquer tamanho, e mais membranosas que as plântulas de $N$. amazonum e, muitas vezes, pode estar ligada ao rizoma (Figs. 10F, G).

Diásporo: fruto simples bacáceo e plurilocular, rompe-se irregularmente na maturação (Barroso et al. 1999), submerso na água; semente globosa, provido de opérculo circular, com sementes envolvidas por arilóide saciforme (Barroso et al. 1999), transparente, com aspecto de vidro; tegumento sem tricomas, mas com ornamentações (Fig. 10H).

\section{Victoria amazonica (Poepp.) J.C. Sowerby}

(Figs. 11A-D)

Erva aquática flutuante fixa (Pott \& Pott 2000) (Fig. 11A). Pertence à família Nymphaeaceae, ordem Nymphaeales (APG IV 2016).

Plântula: diferente da planta madura apresenta folhas sagitadas (Fig. 11B), pode ser confundidas com espécies de Nymphaea e Sagittaria, entretanto apresenta pequenos espinhos abaixo do limbo e no pecíolo (Fig. 11b), e no ambiente ocorre submersa na água.

Diásporo: fruto bacáceo indeiscente globosa, densamente coberto por espinhos (Fig. 11C), com muitas sementes (Arber 1920) (Fig. 11c), submerso na água. Sementes globosas, tegumento rígido e envolvidas por arilo mucilaginoso (Barroso et al. 1999) (Fig. 11D) que acumula ar (Rosa-Osman et al. 2011), coloração que vai do verdeoliva à negras e tamanho semelhante à de uma ervilha (Pott 1998) (Fig. 11d).

\section{Oxycaryum cubense (Poepp. \& Kunth) Lye}

(Figs. 11E-H)

Erva perene inicialmente epífita sobre vegetação aquática (Figs. 11E e G), posteriormente enraíza em material orgânico flutuante formando baceiros, propagase por divisão de touceira, rizoma e estolão (Pott \& Pott 2000). Pertence à família Cyperaceae, ordem Poales (APG IV 2016).

Plântula: semelhante à planta madura, porém em menor tamanho, com folhas filiformes e espiraladas, apresenta-se sobre outras plantas, geralmente Salvinia spp. (Fig. 11F). Diásporo: fruto aquênio; semente elíptica, achatada dorsiventralmente, marrom escura, com base de estilete persistente de ápice acuminado (Fig. 11H).

\section{Thalia geniculata L.}

(Figs. 12A-D)

Erva aquática perene anfíbia (Fig. 12A), tornandose emergente quando na água, propaga-se por rizomas e divisão de touceiras (Pott \& Pott 2000). Pertence à família Marantaceae, ordem Zingiberales (APG IV 2016).

Plântula: versão menor da planta madura, com pecíolos longos e geniculados verdes, porém com folhas simples em forma de lança mais afiladas (Fig. 12B).

Diásporo: fruto espigueta elíptica, em forma de ponta de seta (Fig. 12C); semente oval (parece amendoim), tegumento glabro, duro e cor de caramelo, pode encontrarse envolta por uma membrana estriada e fina (Fig. 12D).

\section{Canna glauca L.}

(Figs. 12E-H)

Erva perene anfíbia, emergente quando em água (Fig. $12 \mathrm{E}$ ), propaga-se por divisão de touceira e rizoma (Pott \& Pott 2000). Pertence à família Cannaceae, ordem Zingiberales (APG IV 2016).

Plântula: apresenta-se semelhante à planta madura, em menor tamanho, com folhas lanceoladas verdes num tom mais claro (glauco) (Fig. 12F).

Diásporo: fruto em cápsula loculicida, globoso e com espinhos (Fig. 12G); semente esferoidal, cor varia de ocre a preto, dura e glabra, pode ter manchas marrons (Fig. 12H).

Este guia de identificação traz informações inéditas para as espécies avaliadas e serve de base para consolidação de estudos ecológicos com comunidades de macrófitas aquáticas. 

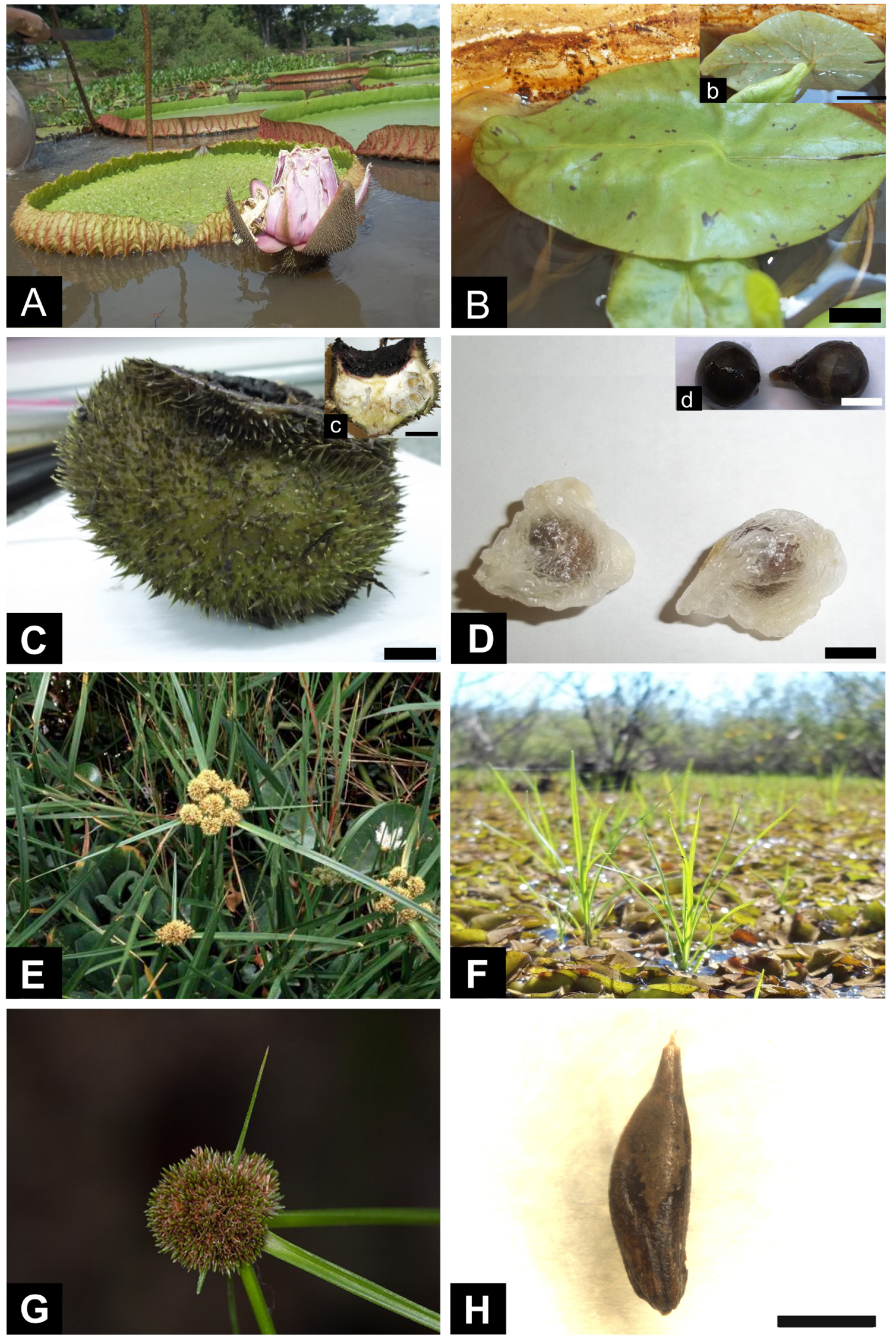

Figs. 11A-H. A-D. Victoria amazônica. A. planta; B. plântula, b. limbo com espinhos; C, c. diásporo; D. semente com arilo gelatinoso; d. semente. E-H. Oxycaryum cubense. E. planta; F. plântula; G. inflorescência; H. semente. Barras: Figs. B, b, C, c, D, d =1 cm; Fig. H=1 mm. 

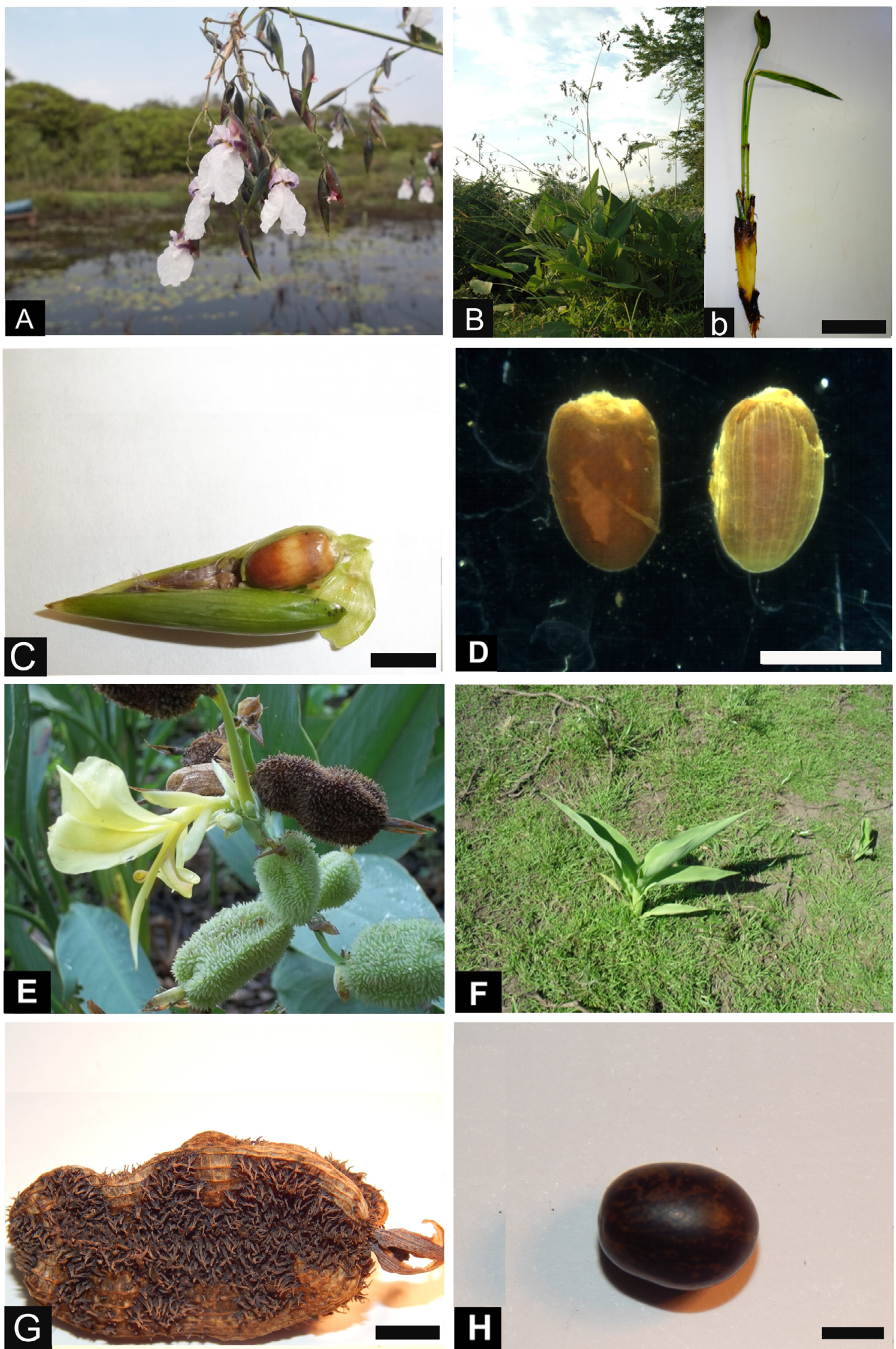

Figs. 12A-H. A-D. Thalia geniculata. A. inflorescência; B. planta; b. plântula; C. diásporo; D. semente. E-H. Canna glauca. E. inflorescência; F. plântula; G. diásporo; H. semente. Barras: Figs. b, C, G, H $=1 \mathrm{~cm}$; Fig. D $=5 \mathrm{~mm}$. 


\section{AGRADECIMENTOS}

Ao Conselho Nacional de Desenvolvimento Científico e Tecnológico $(\mathrm{CNPq})$ à bolsa de PIBIC concedida para o desenvolvimento do projeto.

\section{REFERÊNCIAS}

Abdon, M.M., Silva, J.S.V., Pott, V.J., Pott, A. \& Silva, M.P. 1998. Utilização de dados analógicos do Landsat-Tm na discriminação da vegetação de parte da sub-região da Nhecolândia no Pantanal. Pesquisa Agropecuária Brasileira 33:1799-1813.

Angiosperm Phylogeny Group classification for the orders and families of flowering plants: APG IV 2016. Botanical Journal of the Linnean Society 181(1):1-20.

Arber, A. 1920. Water plants: a study of aquatic angiosperms. University Press, Cambridge. 436 p.

Bacigalupo, N.M. \& Cabral, E.L. 1999. Revisión de las especies americanas del género Diodia (Rubiaceae, Spermacoceae). Darwiniana 37(12):153-165

Baker, H.G. 1989. Some aspects of the natural history of seed banks. In Ecology of soil seed banks (M.A. Leck, T.V. Parker \& R.L. Simpson, eds.). Academic Press, New York, p. 9-21.

Barroso, G.M., Morim, M.P., Peixoto, A.L. \& Ichaso, C.L.F. 1999. Frutos e sementes: morfologia aplicada à sistemática de dicotiledôneas. Universidade Federal de Viçosa, Viçosa. 443 p.

Bonis, A., Lepart, J. \& Grillas, P. 1995. Seed bank dynamics and coexistence of annual macrophytes in a temporary and variable habitat. Oikos 74:81-92.

Cook, C.D.K. 1990. Aquatic plant book. Sciences Publish Corporation, The Hague, Netherlands. 228 p.

Daniel, O. \& Jankauskis, J. 1989. Avaliação de metodologia para o estudo do estoque de sementes do solo. Série Instituto de Pesquisas e Estudos Florestais 41-42:18-26.

Darwall, W., Smith, K., Allen, D., Seddon, M., McGregor Reid, G., Clausnitzer, V. \& Kalkman, V. 2008. Freshwater biodiversity - a hidden resource under threat. In The 2008 review of the IUCN Red List of threatened species (J.C. Vié, C. Hilton-Tylor \& S.N. Stuard, eds.). International Union for Conservation of Nature, Gland. $43 \mathrm{p}$.

Flora do Brasil 2014. Jardim Botânico do Rio de Janeiro. Disponível em: http://floradobrasil.jbrj.gov.br/. Acessado em 10/10/2014.

Guarim, V.L.M.S., Moraes, E.C.C., Prance, G.T. \& Ratter, J.A. 2000. Inventory of a mesotrophic Callisthene cerradão in the Pantanal of Mato Grosso, Brazil. Edinburgh Journal of Botany 57:429-436.

Irgang, B.E. \& Gastal Jr., C.V.S. 1996. Macrófitas aquáticas da planície costeira do RS. Universidade Federal do Rio Grande do Sul, Porto Alegre. $20 \mathrm{p}$.

Junk, W.J., Bayley, P.B. \& Sparks, R.E. 1989. The flood pulse concept in river-floodplain systems. Canadian Special Publication of Fisheries and Aquatic Sciences 106:110-127.

Junk, W.J. \& da Silva, C.J. 1995. Neotropical floodplains: a comparison between the Pantanal of Mato Grosso and the Large Amazonian river floodplains. In Limnology in Brazil (J.G. Tundisi, C.E.M. Bicudo \& T. Matsumura-Tundisi, eds.). Academia Brasileira de Ciências e Sociedade Brasileira de Limnologia, Rio de Janeiro, p. 195-217.

Kissmann, K.G. 1997. Plantas infestantes e nocivas. Tomo 1, BASF, São Paulo. 825 p

Koeppen, W. 1948. Climatologia: con um estudio de los climas de la tierra. Fondo de cultura economica, Mexico. 478 p.

Lima, C.T., Giulietti, A.M. \& Santos, F.A.R. 2012. Flora of Bahia: Cabombaceae. Sitientibus, série Ciências Biológicas 12(1):61-68.

Lima, C.T., Santos, F.A.R. \& Giulietti, A.M. 2014. Morphological strategies of Cabomba (Cabombaceae), a genus of aquatic plants. Acta Botanica Brasilica 28(3):327-338.

Matias, L.Q. 2007. O gênero Echinodorus (Alismataceae) no domínio da caatinga brasileira. Rodriguésia 58(4):743-774.

Matias, L.Q. \& Sousa, D.J.L. de. 2011. Alismataceae in Ceará State, Brazil. Rodriguésia 62(4):887-900

Melo, E. 1996. O gênero Polygonum L. (Polygonaceae) no estado da Bahia, Brasil. Sitientibus 14:45-55.

Nascimento, H.C.E., Andrade, I.M.D., Silva, M.F.S. \& Matias, L.Q. 2013. Pontederiaceae in the coastal region of Piauí, Brazil. Rodriguésia 64(3):625-634.

Pivari, M.O. 2009. Cabombaceae. In Plantas da floresta Atlântica (J.R. Stehmann, R.C. Forzza, A. Salino, M. Sobral, D.D. Costa, L.H.Y. Kamino, eds.). Jardim Botânico do Rio de Janeiro, Rio de Janeiro, v.1, p.1-206.

Pott, V.J. 1998. A família Nymphaeaceae no Pantanal, Mato Grosso e Mato Grosso do Sul, Brasil. Acta Botanica Brasilica 12(2):183-194.

Pott, V.J. \& Pott, A. 2000. Plantas aquáticas do Pantanal. Embrapa, Brasília. $404 \mathrm{p}$

Pozer, C.G. \& Nogueira, F. 2004. Pastagens nativas inundáveis da região norte do Pantanal de Mato Grosso: variações de biomassa e de produtividade primária. Brazilian Journal of Biology 64(4):859-866.

Radam-Brasil. 1982. Projeto Radam-Brasil: Levantamento de Recursos Naturais. Ministério das Minas e Energia, Corumbá, v. 27, 448 p.

Rosa-Osman, S.M.D., Rodrigues, R., Mendonça, M.S.D., Souza, L.A.D. \& Piedade, M.T.F. 2011. Morfologia da flor, fruto e plântula de Victoria amazonica (Poepp.) JC Sowerby (Nymphaeaceae). Acta Amazonica 41(1):21-28.

Secretaria of the Convention on Biodiversity - SCBD. 2010. Disponível em: https://www.cbd.int. Acessado em 10.10.2014.

Schimitz, M.C. 1992. Banco de sementes no solo em áreas do reservatório da UHE Paraibuna. In Recomposição da vegetação com espécies arbóreas nativas em reservatórios de usinas hidrelétricas da CESP (P.Y. Kageyama, ed.). Série Instituto de Pesquisas e Estudos Florestais 8(25):7-8

Silva, J.S.V. \& Abdon, M.M. 1998. Delimitação do Pantanal Brasileiro e suas sub-regiões. Pesquisa Agropecuária Brasileira 33:1703-1711.

Soriano, B.M.A., Clarke, R.T. \& Catella, A.C. 2001. Evolução da erosividade das chuvas na bacia do alto Taquari. Boletim de Pesquisa Embrapa Pantanal, Corumbá, v. 25, 18 p.

Tur, N.M. 1972. Embalsados y camalotes de la Región Isleña Del Paraná Médio. Darwiniana 17:397-407.

Uhl, C., Clark, K., Dezzeo, N. \& Maquirino, P. 1988. Vegetation dynamics in Amazonian treefall gaps. Ecology 69:751-763. 